\title{
La villa romana de Santa Lucía (Aguilafuente, Segovia). Aproximación a su estudio treinta años después de su excavación
}

\author{
IsaAc Sastre de Diego*
}

\section{RESUMEN}

La villa romana de Santa Lucía, en Aguilafuente (Segovia), ha cumplido treinta años de su excavación arqueológica. Durante este tiempo, el yacimiento ha sufrido las consecuencias de un grave deterioro medioambiental, provocando su mala conservación actual.

Se trata de uno de los grandes latifundios bajoimperiales meseteños que se desarrollaron sobre asentamientos rurales precedentes, explotando de forma intensa las actividades económicas de la zona, principalmente agrícola (cerealística) y ganadera.

Las características de su entorno físico la convierten en modelo práctico del tipo de villae con el que teorizaban los agrónomos clásicos. Pese a los valiosos trabajos de R. Lucas y Viñas, falta, sin embargo, un estudio en

\section{ABSTRACT}

The Roman villa of Santa Lucia in Aguilafuente (Segovia), was been thirty years of its archaeological excavation. During this time, the deposit has undergone the consequences of a serious environmental deterioration that has caused its badly present conservation.

It's a matter of the great large states of the landing's Low empire that were developed on preceding rural establishments, operating of intense form the economic activities of the zone, mainly agricultural (of cereal) an cattle activities.

The characteristics of their physical surroundings turn it in a practical model of the type of villae with which the classic agronomists theorized. In spite of the valuable works of $R$. Lucas and Viñas, it lacks, nevertheless, a deep study on this deposit that had an

* Universidad Autónoma de Madrid.

Quiero agradecer a la Dra. Rosario Lucas su ayuda, facilitándome toda la documentación necesaria, así como a los profesores Joaquín Barrio, Manuel Bendala y Carmen Fernández Ochoa sus consejos para la realización de este trabajo. 
profundidad sobre este yacimiento que tuvo una interesante pervivencia en época visigoda.

Próximamente, se desarrollará el estudio de los materiales arqueológicos recogidos en las excavaciones de 1968-1972, que será realizado por J. E. Molina, encargado del Aula Arqueológica de Aguilafuente,

y por mi mismo. interesting survival in Visigothic times. Next the study of the archaeological materials gathered in the excavations from 1968 to 1972 will be developed by $J$. E. Molina, ordered of the Archaeological Classroom of Aguilafuente, and by myself.

No cabe duda de que Segovia es una de las provincias del territorio español que cuenta con mayor riqueza patrimonial. A los conocidos monumentos de tipo histórico-artístico considerados Bienes de Interés Cultural desde hace varios años (como el famoso acueducto romano, su alcázar, o sus iglesias románicas, todo ello reflejado en el nombramiento de la capital como Ciudad Patrimonio de la Humanidad por la UNESCO en 1985), se une el importante valor cultural que tienen varios de sus pueblos, como son Sepúlveda, Cuéllar, Coca o Ayllón.

Sin embargo, hay otra realidad cultural, que también tiene un importante interés histórico, de la que apenas hay un conocimiento meramente superficial. Esta realidad atañe principalmente a diversos yacimientos arqueológicos diseminados por toda la provincia, de los que, si bien hay constancia documental e incluso en algunos de ellos se han podido efectuar excavaciones, su situación en el plano del estudio científico, difusión pública y, sobre todo, conservación del lugar, presenta un panorama preocupante.

Este es el caso de la villa romana de Santa Lucía, situada en el término de Aguilafuente, al NO de Segovia. Excavada entre los años 1968 y 1972, su estado de conservación actual es crítico, pese a que posee bastante interés científico y unas muy buenas condiciones para su difusión cultural y turística, e incluso para futuras labores de excavación y de estudio.

\section{DESCRIPCIÓN GEOGRÁFICA Y FÍSICA DEL YACIMIENTO DE SANTA LUCÍA}

Como acabamos de decir, el yacimiento arqueológico de Santa Lucía se encuentra dentro del término jurídico de Aguilafuente, situado a $35 \mathrm{Km}$ 
al NO de la capital de Segovia. Esta villa está enclavada en la comarca conocida tradicionalmente como «tierra de pinares». Posee una altitud sobre el nivel del mar de $889 \mathrm{~m}$, lo que influye considerablemente en su climatología.

En cuanto a su extensión, Aguilafuente posee un perímetro de unos $5,5 \mathrm{Km}$ aproximadamente. Dentro de su superficie, el yacimiento se halla a $2 \mathrm{Km}$ del pueblo, siguiendo la carretera comarcal que va desde Aguilafuente a Sauquillo de Cabezas ( $\mathrm{Km} 9$ de la Comarcal 222), a unos cien metros de la carretera por su lado N. En la actualidad existen bastantes dificultades para encontrar el yacimiento, ya que no hay señalización alguna y está literalmente rodeado por las tierras de labor.

Geología de la zona

Uno de los aspectos más importantes a tener en cuenta de cara a un buen conocimiento de los componentes constructivos del yacimiento y de los problemas que pueden afectar a las estructuras y su estabilidad, es aquel relacionado con las características geológicas de la zona donde se asienta el conjunto.

De líneas llanas en la mayoría de su extensión, con algunas ondulaciones no superiores a! $3 \%$, Aguilafuente comprende hoy en día extensos pinares, tierras de cultivo, pastizales y praderas, con una composición en algunas zonas de tierras arcillosas que pueden originar ciertos movimientos o cambios bajo la capa superficial que podrían afectar a las estructuras asentadas sobre ellas.

La erosión que sufre su relieve es casi nula, por lo que se producen mínimas alteraciones en el paisaje. Esto nos hace suponer que en el pasado pudo tener un ecosistema parecido, con facilidad para el desarrollo de una vegetación variada, factor éste que tenía gran valor para los agrónomos latinos.

\section{Hidrografía de la zona}

Es necesario conocer cuál es la composición hidrográfica del término de Aguilafuente de cara a su posible influencia en el conjunto; pues, al igual que la riqueza vegetal de la zona, supone un aspecto determinante a la hora de que, en época romana, se decidiera aquí la construcción de una villa que explotase las condiciones del terreno. 
Aunque las estribaciones del Sistema Central están relativamente próximas, el término de Aguilafuente es completamente llano, siendo alterado ligeramente por los cauces hidrográficos del río Cega y el arroyo Malucas, que discurren de este a oeste, así como por numerosos valladares y fuentes naturales ${ }^{1}$.

Así pues, la zona en el aspecto hidrográfico se puede considerar privilegiada. Esa proximidad a las estribaciones del Sistema Central origina dos tipos de corrientes de agua que surcan el término: subterráneas y de superficie.

Dentro de las primeras su afloración se realiza, de forma natural, en fuentes distribuidas por el término. La propia toponimia de Aguilafuente nos habla, bien claramente, de la abundancia de fuentes naturales desde los tiempos antiguos, pudiéndose comprobar, según J. J. Díez Sanz ${ }^{2}$, tanto en el término (Fuente de la Hoyada, San Cristóbal, Santa Lucia, La Poza, etc), como dentro del propio casco urbano (Fuente de San Juan, El Cubón, La Plaza, etc).

Las aguas superficiales son poco aprovechadas en la actualidad, pero seguramente no fue así en el pasado. La corriente más importante es el río Cega, afluente del Duero por su orilla izquierda. Sus aguas discurren en dirección E-O. Hay constancia de su explotación para actividades agrícolas ya en el siglo xV, conservándose un documento de 1498 en el que se habla del establecimiento en sus riberas de molinos harineros y batanes de lana.

La otra gran corriente de agua superficial que atraviesa el término es el arroyo de Malucas, cuyo cauce cruzaba la población (actualmente está seco) provocando, en tiempos pasados, inundaciones de viviendas en las épocas de lluvias. También sus aguas discurrían de E-O. Este es el cauce fluvial que más nos interesa para el estudio de la villa, ya que se encuentra situado a apenas $19 \mathrm{~m}$ de la misma por su lado $\mathrm{S}$.

Por último, también es necesario destacar el gran número de valladares, fuentes y pequeños riachuelos que en época de lluvias recorren los campos, filtrándose en su mayoría, para así ir a engrosar las corrientes subterráneas ${ }^{3}$.

1 Un estudio completo de la geografía de la zona lo encontramos en: DíEZ SANZ, J. J. (2000): Historia de Aguilafuente, 2. ${ }^{a}$ edición, Alcalá de Henares.

2 Dízz Sanz, J. J.: op. Cit.

3 Dízz Sanz, J. J.: op. Cit. 


\section{Climatología}

Al igual que toda la provincia de Segovia, Aguilafuente padece los rigores de un clima continental, típico de la Meseta Castellana.

Los inviernos son muy fríos con temperaturas mínimas absolutas de $-15^{\circ} \mathrm{C}$, siendo las heladas de las noches y las nieves dos fenómenos bien conocidos, desde siempre, por los habitantes de esta villa. Este es uno de los factores de mayor riesgo para la conservación de las estructuras murarias de la villa romana, sobre todo si éstas se encuentran a la intemperie durante todo el año, como es el caso.

Los vientos dominantes son del NO, llamados vientos del «Cierzo», los cuales arrastran hacia el interior todas las inclemencias que penetran por el norte de la Península.

Como vemos, las condiciones climatológicas no son las más favorables para una buena habitabilidad. Ello no fue impedimento, sin embargo, para la construcción en época romana de una villa en estas tierras. No creemos que fuera porque en ese periodo la climatología fuese muy diferente, sino que se debieron valorar una serie de factores que, a la hora de decidir, pesaban más que los condicionantes metereológicos. Además, la situación del yacimiento en relación a su entorno presenta todas las características señaladas por los escritores agrónomos latinos como idóneas para el buen desarrollo y construcción de una villa en el mundo rural, como veremos a continuación.

Por otro lado, conviene destacar que, pese a los condicionantes negativos del clima meseteño, esta zona en torno al Duero es una de las que tiene mayor dispersión de villas hispanorromanas toda la Península.

Sin embargo, desde el punto de vista de la conservación, estas condiciones climáticas suponen para el yacimiento, en su situación actual, serios riesgos que habría que afrontar lo más rápidamente posible.

\section{La villa de Santa Lucía y los textos de los agrónomos latinos}

Ha quedado reflejado en el apartado anterior que el enclave donde se sitúa el yacimiento, pese a la dureza del rigor climático, reúne condiciones naturales excepcionales para el asentamiento humano y su explotación económica, por lo que ha sido habitado en diferentes etapas, como se ha podido documentar por distintas fuentes literarias, así como por las campañas de excavación realizadas en los años setenta. 
Como hemos visto, la zona posee abundante agua potable al existir unas fuentes naturales de gran caudal, incluso en verano. Aparte, en la Antigüedad habría que tener muy en cuenta el discurrir de las aguas del citado arroyo Malucas, a $19 \mathrm{~m}$. de distancia.

Por otro lado, la villa está próxima a una extensa mancha de pinares negrales y monte chaparral con algunas encinas y pinos, «La Mata», y probablemente en época antigua la masa forestal fuera mucho más amplia, por lo que la leña para el fuego y maderas para las construcciones era fácil de obtener.

Desde el punto de vista económico, este yacimiento muy posiblemente se encontraba situado en el centro de una extensa llanura de tierras cerealísticas y de viñedo (producto que actualmente no se cultiva pero que en el siglo XVI está documentado), fáciles de trabajar con los utensilios antiguos. Es más, tanto las extensiones forestales como de cereales, proporcionan abundantes pastos para los animales de los pobladores del paraje.

Todos estos elementos físicos positivos que presenta el territorio circundante al enclave de Santa Lucía ya son comentados por los autores clásicos que escribieron distintas recomendaciones a tener en cuenta sobre la construcción y explotación de las villas. Creemos interesante señalarlas y compararlas con las características geográficas que posee la zona porque consideramos que, al igual que influyeron en la decisión de emplazar la ubicación de la villa en ese lugar, pueden seguir influyendo en la actualidad de cara al conocimiento científico de todo el territorio que podría haber pertenecido a la villa y a la comprensión de determinados factores relacionados con ella que debemos tener presentes para una mejor actuación conservadora y musealizadora, así como para futuras excavaciones en distintos puntos del término cercanos al yacimiento, teniendo en cuenta, como ya se sabe y como los propios autores clásicos reflejan, que una villa no era sólo la pars urbana, sino que esto realmente era una pequeña parte de una gran cantidad de estructuras, más o menos lejanas y más o menos funcionales, relacionadas con el edificio residencial y que estarían diseminadas por todo el fundus o propiedad ${ }^{4}$.

Lo primero que debemos mencionar es que era general el que los diversos escritores romanos que realizaron trabajos sobre el mundo del

\footnotetext{
4 Fernández Castro, M.a. C. (1982): Las villas romanas en España. Ministerio de Cultura, Dirección General de Bellas Artes, Madrid.
} 
campo, como Catón, Columella o Palladio, hablasen de las condiciones que debía de tener un terreno para convertirse en una buena villa y sacarle el mayor rendimiento posible.

El requisito primordial para la implantación de una explotación de tipo económico en el ámbito rural y, a la vez, residencia de descanso, según estos autores, era el de la calidad de la tierra.

"Cuando vayas a comprar una finca - aconsejaba el viejo Catón- visita varias veces el lugar elegido y mira bien a tu alrededor... Asegúrate de que tienes buen clima, no propenso a tormentas. El terreno ha de ser bueno, con fortaleza natural. Si fuese posible, debería hallarse al pie de una colina, orientado a mediodía, en un lugar sano y donde resulte fácil encontrar peones. Debe tener agua abundante y encontrarse cerca de una población floreciente, o del mar o de un río navegable, o de una calzada buena y frecuentada (...) Si me preguntas cuál es la finca ideal, te diré que la de cien yugadas (250.000 metros cuadrados) de extensión y dotada de toda clase de suelos. Lo primero ha de ser la viña, si produce vino de buena calidad; lo segundo, un huerto irrigado; lo tercero, un sauceda; lo cuarto un olivar; lo quinto, un prado; lo sexto, un campo de trigo; lo séptimo un bosque; lo octavo, una arboleda; lo noveno, un encinar» (Catón, De agricultura. I, 1,3 y 7,1 ).

Así pues, si tomamos el texto de Catón como guía, podemos observar que la villa de Aguilafuente reúne bastantes de sus consejos. En lo único que pudiera estar más alejada del autor latino es en lo referente al buen clima. De todas formas, el hecho de situarse en las estribaciones de la Sierra, es decir, ya alejada de la zona montañosa y más próxima a la cuenca del Duero, la hace más fértil y con menor dureza a la hora de afrontar las estaciones más frías.

Por otra parte, aunque no se halle al pie de una colina, si está situada en un pequeño montículo (el único que hay en la zona) dominando la llanura que se extiende por todos sus lados.

La orientación que pide Catón la cumple, situándose la villa afrontada hacia el sur.

En cuanto al agua, ya hemos visto que este no es precisamente ningún problema en la zona, encontrándose situada de forma estratégica entre dos cursos fluviales, uno que sería de utilización directa en la vida de la residencia o vivienda del señor, como es el arroyo Malucas; y otro más destinado a la explotación agrícola, como sería el río Cega, a escasos $4 \mathrm{Km}$ al norte de Santa Lucía.

En relación con la necesidad de que hubiera una vía de comunicación en las cercanías de la villa, preferentemente secundaria para que no tenga 
mucho trasiego de personas, pero lo suficientemente próxima a una vía principal para poder utilizarla a nivel comercial, hay que decir que, de época romana, se conoce la existencia de un camino a $150 \mathrm{~m}$. por el cual actualmente pasa una carretera, lo que facilitaba el acceso a las vías de comunicación permitiendo a estos asentamientos una fácil exportación de los productos excedentarios: trigo, vino, etc., y la llegada de aquellos en que eran deficitarios (como el aceite).

Este camino partía desde Cauca (Coca) hasta Torodano (Turégano), pasando por Vagilafont (Aguilafuente) y ¿Suqario? (Sauquillo?), uniéndose con el ramal que conducía desde Turégano a Buitrago, según datos del historiador del siglo XVI Diego de Colmenares: "que vadit de Torodano a Butrac" ${ }^{5}$.

Otro ramal partía desde Turégano hasta Soto Albos (la actual Sotosalbos) a Collado Hermoso "Collad Formoso», donde se encuentran las fuentes del río Pirón y pasando el puerto Carpetano de Navafría llegaba a las fuentes del río Lozoya.

Otro de los aspectos que tiene en cuenta Catón es la existencia de diferentes tipos de árboles que integren la masa forestal de la explotación rural. Prima la variedad de especies (robles, encinas, sauces, etc). Aunque este es, quizá, el punto más difícil de conocer por el gran cambio que ha sufrido el paisaje segoviano durante la Edad Moderna y Contemporánea, y admitiendo que nos movemos en el plano de la mera especulación, nos gustaría señalar la existencia de numerosos topónimos, situados en un radio de 2 a $4 \mathrm{Km}$ alrededor de la villa, que hacen referencia a diferentes especies vegetales que, por lo peculiar de su presencia en estas zonas o lo propio de su localización, han quedado plasmados a la hora de denominar los parajes. Este es el caso del nombre del pueblo de Sauquillo de Cabezas, a tan solo $3 \mathrm{Km}$ de Santa Lucía, y que hace alusión, sin lugar a dudas, a la especie del saúco, como muy bien explica Pedro Luis Siguero Llorente en su obra Significado de los nombres de los pueblos y despoblados de Segovia $(1997)^{6}$.

Muy cerca de Sauquillo, a unos $500 \mathrm{~m}$ por su lado $\mathrm{N}$, nos encontramos con un lugar llamado Rebollar. Volviendo a tomar como referencia a P.L.

5 De Colmenares, D. (1990): Historia de la insigne ciudad de Segovia. Reeditado por Caja Segovia, Segovia.

6 Este autor nos dice que: «Sauquillo de Cabezas se llama de Cabezas sólo desde 1845, debido a que pertenecía al Sexmo de Cabezas de la Comunidad de Segovia. Antes era simplemente Sauquillo. En 1247 se menciona ya como Sauquiello. Significa «el saúco pequeño». El saúco es un arbusto que siempre aparece en las cercanías de los ríos o de los arroyos. Su nombre deriva del latín sambucus.» 
Siguero, un rebollar significa: «bosque de robles rebollos o melojos. El nombre deriva del latín robur pullus, «roble joven», debido a que este roble rebrota mucho de cepa, y por lo tanto siempre tiene muchos renuevos. Este roble vive de 1200 a 1500 metros, por eso es un árbol más típico de la Sierra, y la existencia de un rebollar tan lejos de la Sierra era un hecho atípico que por tanto tenía gran utilidad para identificar el lugar. Si recordamos, la altura de Aguilafuente no alcanzaba los $900 \mathrm{~m}$ sobre el nivel del mar, por lo que se cumplen las palabras de Siguero Llorente, y, en nuestro caso, se decidió denominar a un paraje con el nombre de la especie arbórea que resulta más típica de otras zonas situadas a bastantes kilómetros de Aguilafuente. Estos dos casos no son los únicos (pimpollar, por supuesto numerosas referencias a los pinares, etc.) pero sí son los más ejemplificadores de una realidad forestal que, por lo menos en el siglo XIII, tendía a la riqueza y variedad. No obstante, somos conscientes de lo complicado que resulta extrapolar esta situación a la época romana. Sin embargo, no nos resistimos a comentarlo aunque sólo sea como hipótesis de trabajo para investigaciones futuras y a considerarlo interesante en un posible proyecto de repoblación de una pequeña pero representativa masa forestal asociado a la creación de un parque arqueológico en la villa de Santa Lucía.

Pero es en la necesidad de conseguir tierras "salubres», de gran calidad, en lo que más énfasis ponen los agrónomos clásicos.

Este interés por la salubridad de la tierra está puesto en estrecha relación con el buen conocimiento de la climatología de la zona. Casi todos los escritores están de acuerdo en decir que de antemano, y antes de comprar un terreno que sea insalubre o estéril (Columela, 1,4,2), han de conocerse los vientos, las variaciones de la atmósfera y los usos del país con respecto al cultivo. Como ya dijimos más atrás, lo más conveniente es, en principio, construir al pie de una colina y preferentemente a media altura (Varrón, I,12,1). De esta forma, el lugar elegido no se helará en invierno ni se abrasará en verano (Columela, I,4,10). Tampoco ha de exponerse la edificación a la violencia del viento o de la lluvia en la cima de las montañas. Una posición más elevada que el resto del terreno es la más sana y mejor: protege la casa contra la penetración de insectos (Varrón, I,12,3); disipa, si hubiera, las emanaciones subterráneas, e impide que un torrente descendiente de la colina conmueva los cimientos de la casa. Este es el caso de la situación de Santa Lucía con respecto al marco geográfico en el que se asienta, como hemos visto.

Por otra parte, este peligro de conmoción de las cimentaciones denota ya una preocupación seria en época romana por la estabilidad y buena 
conservación de los muros y nos es de gran ayuda para posibles intervenciones en la actualidad. Además, no es el único peligro que se evita con la ubicación en altura. También los riesgos de las inundaciones, los desbordamientos de los ríos y hasta los improvisados ataques de los ladrones.

Como conclusión, podemos decir que la situación de la villa de Santa Lucía y su marco geográfico se ajustan en un alto porcentaje a las recomendaciones hechas por los autores clásicos. Además, muchos de sus consejos (que por otro lado vemos como permanecen invariables desde el siglo II a.C. con Catón hasta el siglo IV d.C con Paladio) han podido repercutir positivamente en el grado de conservación y estabilidad en el que han llegado los muros de la villa hasta su excavación y consecuente salida a la superficie, iniciándose desde entonces un proceso imparable, de momento, de degradación en los últimos treinta años.

\section{EL DESCUBRIMIENTO DE LA VILLA Y SU EXCAVACIÓN ARQUEOLÓGICA (1968-1972)}

La villa de Santa Lucía es llamada así por el nombre del paraje donde se descubrió, aunque parece ser que hasta finales del siglo XVIII este mismo lugar era conocido como San Mamés. En cualquier caso está clara su adscripción a una advocación religiosa, lo que ya, de por sí, denota cierta importancia de la zona como posible lugar donde hubiera existido algún tipo de edificación eclesiástica 0 , por lo menos, de culto en el pasado.

El yacimiento tiene una extensión de unos $2500 \mathrm{Km}^{2}$ (formando una planta más o menos cuadrada de $50 \times 50 \mathrm{~m}$ ), aunque la parte excavada sólo se refiere a la mitad oeste de lo que seguramente fuera la pars urbana de la villa (fig. 1).

Pese a lo sugerente de varios topónimos de la zona7, el conocimiento de la villa y de su emplazamiento fue cayendo poco a poco en el olvido; siendo su descubrimiento, a fines del siglo XIX, totalmente fortuito. De todas

\footnotetext{
7 Incluido, además de topónimos como el "Cerro de Roma» o «El Sexmo romano", el propio nombre de Aguilafuente, que aparece escrito en los primeros documentos conservados (siglo XII) como Baguilafont, es decir: «la fuente de Baguila». Este sustantivo posee una terminación típica de los nombres de género masculino visigodos (Egila, Suintila, etc.), por lo que pudiera ser ese su origen y relacionarse, por tanto, con la población que debió asentarse en algún lugar cercano a la necrópolis que amortizó la villa ya en el siglo vı d.C., sin tener más argumentos para esta hipótesis que la comparación con la prosopografía de época visigoda.
} 


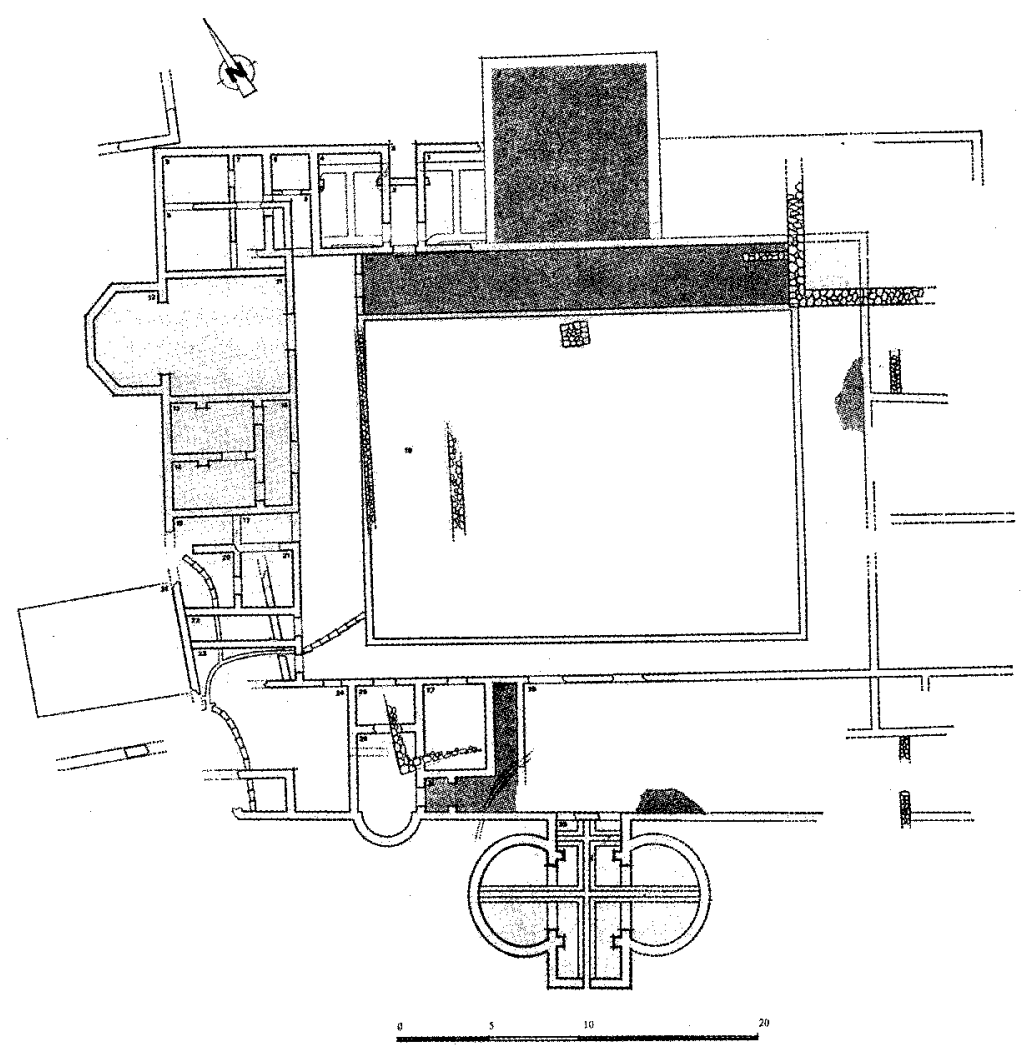

Figura 1.

formas, conviene señalar las noticias que sobre diferentes restos aparecidos y edificaciones existentes en torno al paraje de Santa Lucía se suceden a lo largo de la historia. Así, aparecen ya en la Edad Moderna distintas noticias sobre posibles edificaciones religiosas de origen medieval que tienen como enclave el lugar donde se sitúa la entonces desconocida villa romana.

El que esta edificación fuera un convento templario, como piensan algunos autores, tiene su origen en los rumores de los pobladores de la zona recogidos por el cronista segoviano de comienzos del siglo pasado, Carlos Lecea:

«Es fama en la comarca que en ese mismo punto (Santa Lucía) existió un convento o casa de templarios, designándose aún el sitio que ocupaba la huerta del edificio.» 
Esta información nos la da a raíz del descubrimiento de la villa en 1868. También el historiador del siglo Xvı Diego de Colmenares, en su Historia de la insigne ciudad de Segovia, habla de la donación que en 1137 hizo D. Alfonso VII «el Emperador», a un arcediano llamado D. Pedro, sobrino del obispo, de:

«illam villan cui nomen est Salcedon quae est inter Baguilafont et Cegam ad parietes de Santa Tevala et de illa semita quae vadit de Torodano per Cantaleia ad Fontedonam et usque ad labores de torrecilla et ad Poleiosas cum introtribus...»

Según opina Lecea, los anteriores datos parecen estar hablando de Santa. Lucía: "por su proximidad a los pinares de Aguilafuente, al río Cega y al camino de Turégano a Fuentidueña por Cantalejo».

Antonio Molinero, a mediados del siglo xx, en su obra: Aportaciones de las excavaciones y hallazgos casuales nos ofrece la fotografía de un pináculo gótico y un fragmento arquitectónico procedente de las ruinas de Santa Lucía. Este dato aporta una mayor fuerza a la leyenda de un convento, templario o no, al demostrar la existencia de un edificio encuadrado por dichos materiales entre los siglos XIII y XIV, aunque tampoco se debe descartar el que éstos fueran depositados allí, abandonados por cualquier causa.

J. J. Díez Sanz ${ }^{8}$ va más allá y comenta que «de lo que no parece haber duda es de la existencia de un edificio medieval, utilizando los restos de la antigua villa romana. Esto confirmaría la teoría de Bartolomé Bennasar sobre la explotación, por eclesiásticos, de tierras de antiguas villas romanas».

Hubiera habido o no una edificación religiosa en época medieval, no existe ninguna mención a lo largo de estos siglos de que se tuviera conocimiento de la existencia en la zona de algún tipo de construcción anterior a la Edad Media o, por lo menos, de época tardoantigua. Sólo Carlos Lecea nos habla, a comienzos del siglo xx, del conocimiento, por parte de los más ancianos de la localidad, de una ermita dedicada a Santa Lucía en el lugar donde se encuentra la villa romana. Gracias a los archivos parroquiales se puede documentar que dicha ermita ya estaba construida a fines del siglo XV, pero, como hemos dicho anteriormente, con el nombre de San Mamés?.

8 Dízz Sanz, J. J.: op. Cit.

9 Sí está documentada, aunque en otra localidad segoviana, la presencia del culto o advocación a este santo, que, además, es uno de los mártires más antiguos del santoral cristiano, lo que 
Sin embargo, todos estos datos, a la espera de una futura excavación, quedan por confirmar desde el punto de vista arqueológico y de su registro material.

Refiriéndonos ya de forma concreta a la villa de Santa Lucía, su descubrimiento tuvo lugar en el verano de 1868 , cuando un agricultor, vecino de la localidad, al realizar tareas de arado en un pequeño montículo de este paraje encuentra unos cimientos de construcción al final de los cuales aparecen vistosos mosaicos romanos.

Los hallazgos se hubieran terminado olvidando si no llega a ser porque C. Lecea en su Miscelánea recoge el informe leído en la Real Academia de la Historia por D. Pedro Sabau, en fecha 7 de junio de 1868. En él se comunica la aparición fortuita, durante los trabajos agrícolas, de «dos preciosos mosaicos de grandes dimensiones» en la villa de Aguilafuente.

Estos descubrimientos dieron lugar a algunas excavaciones que por circunstancias históricas (en ese año se produce la Revolución llamada "La Gloriosa") y falta de medios se abandonaron, tapándose el hallazgo con la vuelta al cultivo habitual de la finca.

Gracias a la conservación de toda esa documentación, justo cien años más tarde, el grupo escolar de Misión Rescate número 349, que formaba parte de un programa-concurso cultural ofrecido en aquel tiempo por Radio Televisión Española, reanudó los trabajos con la colaboración del Ayuntamiento de la localidad, llegándose al afloramiento de los mosaicos descritos en la crónica de 1868.

Puesto el hecho en conocimiento de la Dirección General de Bellas Artes, comenzaron finalmente las excavaciones de una manera científica bajo la dirección de los arqueólogos $R$. Lucas Pellicer, actualmente catedrática de Prehistoria de la UAM y Vicente Viñas, que permitieron el descubrimiento de una importante villa romana y de una necrópolis visigoda de gran extensión que la amortiza en un momento posterior.

Las campañas de excavaciones dirigidas por los dos arqueólogos se suceden ininterrumpidamente de 1968 a 1972, año en el que se efectúa la última fase de actuación.

ayudaría a defender una hipotética existencia en época tardoantigua de una edificación religiosa con esta dedicación. Nos referimos a un documento que se encuentra en la catedral de Segovia y que menciona una donación en 1116 al monasterio de Sacramenia de Sancto Momete. En 1181 Alfonso VIll confirma a Sacramenia la posesión del «villari quod vocatur San Mames» (REPRESA, A., La tierra medieval de Segovia, 1979). San Mamés fue mártir en Capadocia, muerto en 273. 
Pese a que sí estaba prevista su continuación, por diferentes problemas las excavaciones se interrumpieron en 1972, sin volverse a retomar desde entonces, quedando algo menos de la mitad de la villa por descubrir.

Desafortunadamente, no se pudo realizar la memoria de excavación del yacimiento, faltándonos ese documento necesario para la comprensión, lo más completa posible, de la actividad histórica del yacimiento. No obstante, sí se publicaron en los años sucesivos una serie de trabajos que nos permiten conocer parcialmente los resultados de las actuaciones que se practicaron. Así, en ellos ${ }^{10}$ los autores hablan de dos fases principales de ocupación del lugar: una primera relacionada con la villa, cuyo momento de esplendor se ha venido estableciendo en torno al siglo IV d.C.; y una segunda fase en la que se documenta la reutilización de la villa como necrópolis de una población visigoda que se asentaría en algún lugar cercano que no se ha podido documentar.

\section{ALGUNAS CUESTIONES SIN RESOLVER DEL YACIMIENTO DE SANTA LUCÍA}

Como acabamos de ver, hasta 1968 no se produjeron excavaciones con rigor científico.

En cuanto a las dos ocupaciones mejor definidas del conjunto que se excavó, se pueden establecer varias cuestiones de difícil solución en la situación actual, algunas de ellas ya planteadas en su momento por R. Lucas y V. Viñas:

1. Con respecto a la edificación romana, sus límites geográficos (no tenemos elementos de juicio, hoy en día, para saber cuál era el espacio ocupado por la pars fructuaria, es decir: almacenes, bodegas, cuadras, habitaciones de servicio, etc.) y cronológicos son imprecisos. Incluso queda abierta la hipótesis de que existiera un primer asentamiento altoimperial (se sabe que en la zona apareció fuera de excavación una moneda de época de Antonino Pio, además de ciertas improntas de muros con di-

10 LUCAS, R. y VINAA, V.: «La villa romana de Aguilafuente (Segovia)», en Segovia. Symposium de Arqueología Romana. Bimilenario de Segovia. Universidad de Barcelona y Caja de Ahorros de Segovia, Publicaciones Eventuales n. 27, Barcelona, 1977. págs. 239-255. Este es, sin duda, el trabajo más completo de los publicados por los directores de la excavación y que palía, en parte, la ausencia de la memoria de excavación. En él se describen cada una de las estancias del conjunto, así como los distintos niveles de excavación encontrados. El resto de las publicaciones se centran principalmente en las pinturas y los mosaicos descubiertos y en el tipo de motivos decorativos que representan. 
ferente orientación que los pertenecientes a la construcción cons derada del siglo IV d.C, pero que están casi totalmente perdidos).

2. En cuanto a la necrópolis visigoda, que se extiende por el área excavada de la villa romana, rebasando su límite más occidental, zona donde, según $R$. Lucas y $V$. Viñas ${ }^{11}$ más y mejor se conservaban las tumbas (que en total ascienden a 198 individuos), el principal problema, como ya hemos señalado, es el desconocimiento de dónde se situaría el hábitat de esta población enterrada en la antigua villa ${ }^{12}$.

Aparte, y teniendo siempre en cuenta las conclusiones de R. Lucas y V. Viñas y las noticias de época moderna citadas en el anterior apartado, es posible que existiesen otras edificaciones posteriores, y que éstas pudieran relacionarse con algunos restos de muros aparecidos en la excavación, pero siempre sin poder asegurar nada debido a su estado de ruina casi total, reducida a unos toscos cimientos o huellas de muro, imposibles de delimitar.

En cuanto a los materiales y restos decorativos encontrados, los pocos restos de mosaicos conservados son, junto con el panel pintado que representa a dos aves enfrentadas y un caballo ${ }^{13}$ (fig. 2), los hallazgos más espectaculares del yacimiento, por lo que fueron arrancados en el momento de la excavación ${ }^{14}$, y llevados primero al Instituto Central de Restauración de Madrid y posteriormente al Museo Provincial de Segovia ${ }^{15}$. Hoy día, las Cartas Internacionales del Restauro recomiendan

11 LuCAS, R. y VINAS, V.: op. Cit.

12 Es interesante reflejar el hallazgo del que da noticia J.J. Díez Sanz en su libro ya citado: «En este sentido, cabe reseñar que en el año de 1975 y realizando tareas de pavimentación de la calle «La Ermita», así como de cimentación de algunas casas que conforman dicha calle, aparecieron gran cantidad de huesos sueltos e incluso enterramientos enteros, no valorados en principio. Pero el descubrimiento de un sarcófago de piedra, tallado en su interior, y otros restos: una cruz de piedra, trozos pequeños de cornisa, etc., hace pensar en el valor arqueológico de lo que allí estaba saliendo. Indagaciones en terrenos de otras casas limítrofes permitieron comprobar la importante dimensión de esta necrópolis. Lo aquí descubierto, nos lleva a la suposición de estar ante una necrópolis visigoda con reutilización de materiales romanos, caso del sarcófago encontrado. La falta de una excavación sistemática por expertos y la pérdida de los objetos aportados, no valorados en su momento, no permiten una afirmación más concreta de los vestigios allí descubiertos".

13 VV.AA. (2000): Segovia Romana, Caja Segovia, Segovia, pág.47.

14 Hay que tener en cuenta que esta acción era lo común por esos años, en los que primaba la recuperación y traslado de los mosaicos a los respectivos museos provinciales sobre el intento de cualquier consolidación y conservación in situ, como se practica actualmente. En este sentido, R. Lucas siguió los consejos dados por M. Almagro, director entonces de la Dirección General de Bellas Artes.

15 Los mosaicos principales, como es el del emblema con los caballos, se encuentran actualmente en el Aula Arqueológica de Aguilafuente, mientras que la pintura continúa en el Museo Provincial de Segovia, cerrado en estos momentos. 


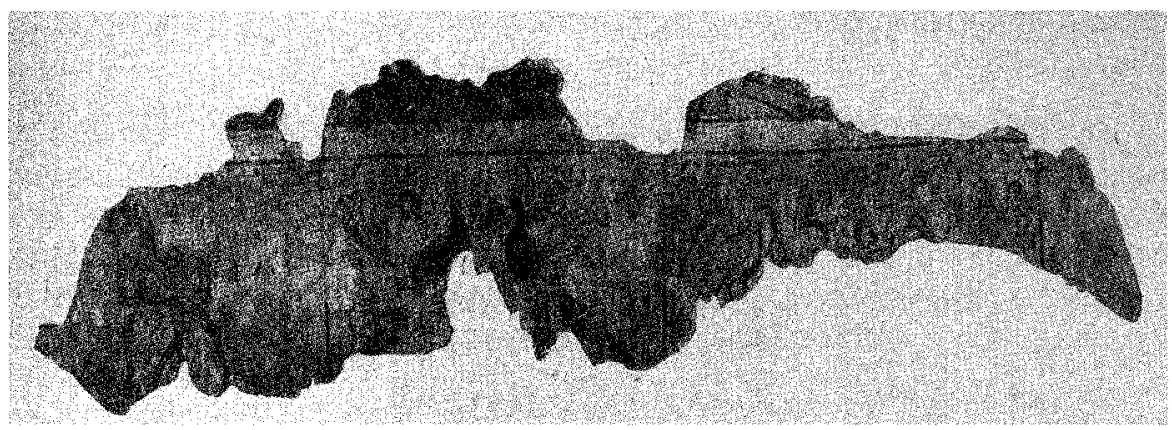

Figura 2.

que se separe la mínima cantidad posible de información de su contexto original, sobre todo si se trata de este tipo de soporte como es el mosaico, por lo que se aconseja su consolidación y restauración in situ, como se está haciendo en la mayoría de los yacimientos.

Por último, uno de los principales problemas que nos encontramos es el estado de arrasamiento de los muros a un mismo nivel, lo que lleva a suponer, como en otras villas, un tipo de paredes de adobe por encima de los basamentos de piedra, o bien el uso de tapial a partir de un cierto nivel de altura. No tenemos ningún elemento de juicio en que apoyarnos, a excepción de la igualdad de la superficie y de la uniformidad de enrasado que se puede comprobar en ciertos tramos. Por otra parte, la piedra encontrada en el relleno de los niveles de excavación no es tan abundante como para pensar en un alzado de piedra, aunque tenemos que tener en cuenta los posibles saqueos y la dedicación de las ruinas a tierras de labor. De todas formas, es una incógnita que, de momento, nos parece difícil de aclarar. No obstante, sí quisiéramos reseñar que en la iglesia románica de San Juan, dentro del pueblo, hemos documentado al menos dos grandes sillares regulares de caliza con agujeros que podrían pertenecer a los forces romanos (figs. 3 y 4). De adscribirse a esta época, nos podría estar indicando la existencia de una estructura o construcción, previsiblemente en la propia villa, de mayor magnitud e importancia con respecto al resto del conjunto.

4. ESTADO DE CONSERVACIÓN ACTUAL DEL YACIMIENTO Y NUEVAS PERSPECTIVAS DE FUTURO PARA EL YACIMIENTO

Tras la finalización de las campañas de excavación, desde 1972 el yacimiento arqueológico de Santa Lucía empezó a sufrir el mismo aban- 


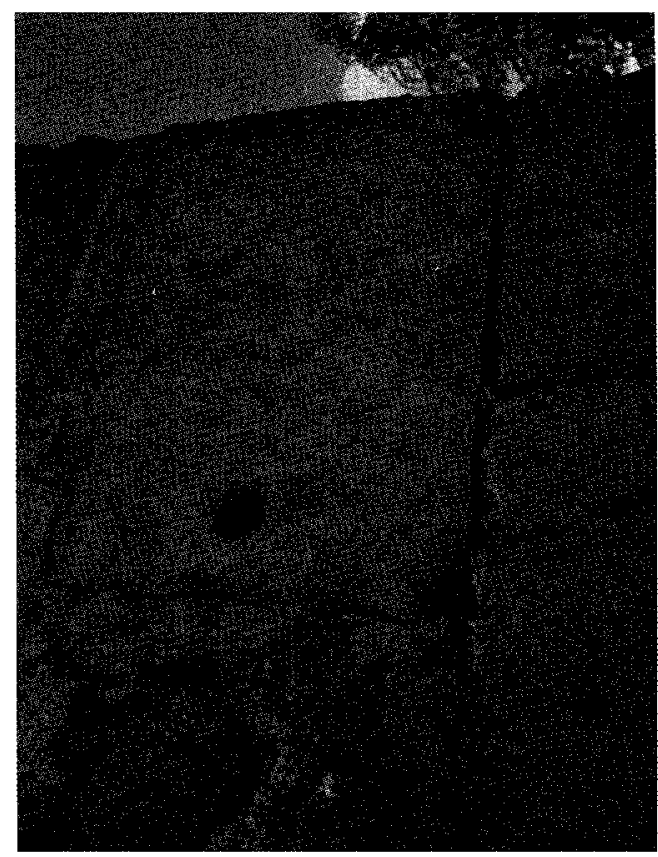

Figura 3.

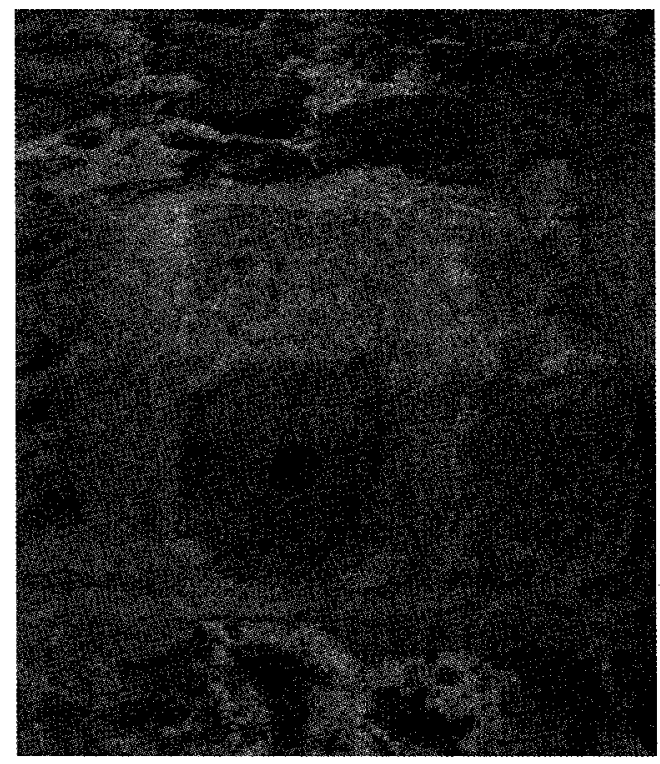

Figura 4. 
dono y olvido que había experimentado cien años atrás cuando se decidió tapar el hallazgo de los mosaicos. La historia se repite y, como entonces, se vuelve a aprovechar la tierra de las inmediaciones (hasta en las zonas más inmediatas a la villa) para el cultivo agrícola. Con el paso de los años, incluso se termina borrando el camino por donde se accedía al yacimiento.

Los efectos de la degradación son cada vez más evidentes. Es por eso por lo que en 1993 se da la voz de alarma y la Junta de Castilla y León decide acometer obras de consolidación en la villa dentro del Programa Anual de la Consejería de Fomento.

El concurso lo ganó la empresa soriana "Arqueotipo". A ella se debe una serie de medidas preventivas que, si bien no han podido frenar el proceso de degradación del yacimiento, sí han supuesto unas mejoras de carácter básico en las condiciones de la villa ${ }^{16}$.

Esta actuación de 1993 fue la primera y la última realizada sobre la villa de Santa Lucía, no resolviendo ningún problema de fondo y quedándose, a nuestro juicio, en un simple «maquillaje» de una realidad mucho más preocupante.

Por tanto, una vez suspendidas las campañas de excavación hace ahora justo treinta años, apenas se han realizado labores de conservación y mucho menos de acondicionamiento del yacimiento. Por eso, actualmente la pérdida es doble: por un lado se está perdiendo el propio yacimiento como consecuencia de la fuerte degradación y abandono al que está sometido de manera intensa. Por otro lado, se ha perdido durante todo este tiempo la oportunidad de haber acondicionado y preparado la villa para el turismo, esto es, su musealización, desaprovechando el término de Aguilafuente un reclamo turístico importante que hubiera ayudado seguramente a preservar mejor el conjunto arqueológico.

16 Gracias a esta intervención se taparon todos los sondeos y estancias mediante un sistema de cubrición con gravilla o cantos de río, colocando después una capa de geotextil y sobre ésta otro nivel de grava. También hubo un intento de consolidación de los muros mediante la creación de una lechada superior de mampuesto con cal y arena, totalmente reversible en ese aspecto, pero que en muchas partes, nueve años después, está totalmente suelta y las piedras del mampuesto desprendidas.

No se ha publicado ningún documento sobre esta actuación, que nosotros tengamos constancia, pero la memoria se puede consultar en $\epsilon !$ archivo del pueblo.

Por ella, supimos que además de las labores de conservación, se realizaron dos sondeos arqueológicos a modo de pequeñas catas. Una se hizo en la zona central del patio, y la otra junto al muro en forma de $L$ del lado NE. Los resultados en ambas se resumen en la aparición de tumbas que formarían parte de la necrópolis vísigoda. 
Ni siquiera existe algún tipo de señalización, ya sea en el pueblo, ya sea en el propio lugar. Además, como ya dijimos, el antiguo camino que conducía a Santa Lucía ha sido literalmente comido por las tierras de labor que están rodeando al yacimiento.

Una vez conseguido llegar hasta el lugar, nos encontramos con un panorama verdaderamente desolador que nos hace darnos cuenta del estado crítico en el que se encuentra la villa romana de Santa Lucía. Y es que muchos de los muros están completamente arrasados a nivel del suelo e invadidos por multitud de plantas superiores, líquenes y musgos de todo tipo. A esto hay que añadir el hecho de que el yacimiento se encuentra a la intemperie durante todo el año, expuesto a las duras condiciones climáticas de esta zona meseteña, así como a bruscos cambios de temperatura y heladas que no hacen sino «dinamitar» el interior de los muros (fig. 5).

Finalmente, hay que tener muy en cuenta la intensa actividad destructora que ha sufrido el yacimiento a lo largo de toda su historia, como se muestra en el siguiente cuadro cronológico con las distintas fases históricas de actividad o intervención en el paraje de Santa Lucía tras su desuso como villa.

Este cuadro cronológico nos ofrece desgraciadamente una situación demasiado activa, hablando en términos de alteraciones, de la villa a lo

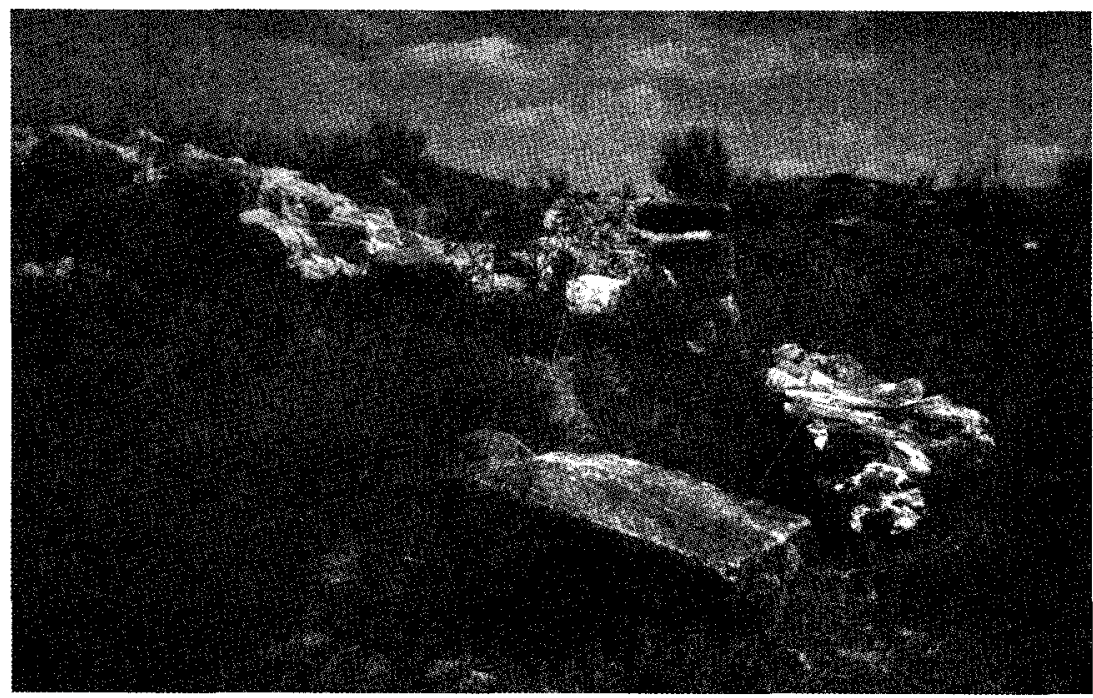

Figura 5. 


\begin{tabular}{|c|c|c|}
\hline Fase I & Abandono de la villa. Siglo $\vee$ d.C & $\begin{array}{l}\text { Posible desaparición de las paredes de } \\
\text { adobe por la acción del clima y el tiem- } \\
\text { po. Reutilización de materiales? }\end{array}$ \\
\hline Fase II & $\begin{array}{l}\text { Reutilización como necrópolis } \\
\text { Siglo vi d.C.-vII d.C. }\end{array}$ & $\begin{array}{l}\text { Destrucción de algunos muros y suelos } \\
\text { para colocar las tumbas. Reutilización } \\
\text { de materiales? }\end{array}$ \\
\hline Fase III & $\begin{array}{l}\text { Edificaciones medievales? Siglos } \\
\text { XII-XIV? }\end{array}$ & $\begin{array}{l}\text { Superposición y destrucción de muros? } \\
\text { Reutilización de materiales? }\end{array}$ \\
\hline Fase IV & $\begin{array}{l}\text { Abandono de las posibles edifica- } \\
\text { ciones medievales. Siglos } x V-X V I I ?\end{array}$ & $\begin{array}{l}\text { Explotación del terreno para labores } \\
\text { agrícolas. } \\
\text { Remoción de tierras y materiales (pie- } \\
\text { dras de los mampuestos). }\end{array}$ \\
\hline Fase V & $\begin{array}{l}\text { Descubrimiento de los mosaicos y } \\
\text { muros. } \\
1868 \text {. }\end{array}$ & $\begin{array}{l}\text { Alteración del equilibrio alcanzado con } \\
\text { el medio durante su fase de enterra- } \\
\text { miento. }\end{array}$ \\
\hline Fase VI & $\begin{array}{l}\text { Labores arqueológicas } \\
1868 ?\end{array}$ & $\begin{array}{l}\text { Desconocemos las actuaciones llevadas } \\
\text { a cabo. }\end{array}$ \\
\hline Fase VII & $\begin{array}{l}\text { Enterramiento del yacimiento y } \\
\text { vuelta a los trabajos agrícolas. } \\
1868-1968 .\end{array}$ & $\begin{array}{l}\text { Remociones ocasionadas por el arado. } \\
\text { Expolios tras conocerse la existencia en } \\
\text { el lugar de objetos antiguos. }\end{array}$ \\
\hline Fase VIII & $\begin{array}{l}\text { Desenterramiento de partes del } \\
\text { yacimiento por «Misión Rescate». } \\
1968 \text {. }\end{array}$ & $\begin{array}{l}\text { Remociones de tierras y perforaciones } \\
\text { no científicas del suelo. "Campo lunar». } \\
\text { Posibles destrucciones. }\end{array}$ \\
\hline Fase IX & $\begin{array}{l}\text { Excavaciones arqueológicas. } \\
\text { 1968-1972. }\end{array}$ & $\begin{array}{l}\text { Alteración de nuevo del equilibrio al } \\
\text { quedarse las estructuras al aire libre. } \\
\text { Traslado de los mosaicos y pinturas al } \\
\text { Museo, }\end{array}$ \\
\hline Fase $\mathrm{X}$ & $\begin{array}{l}\text { Abandono del yacimiento } \\
1972-1993\end{array}$ & $\begin{array}{l}\text { Alteraciones de todo tipo. } \\
\text { Degradación crítica de las estructuras. }\end{array}$ \\
\hline Fase $\mathrm{XI}$ & $\begin{array}{l}\text { Intervención de la Junta de } \\
\text { Castilla y León. } \\
1993\end{array}$ & $\begin{array}{l}\text { Actuación de tipo preventivo. } \\
\text { Consolidación de los muros y cubrición } \\
\text { de las estancias. }\end{array}$ \\
\hline Fase XII & $\begin{array}{l}\text { Abandono del yacimiento. } \\
1993-2002\end{array}$ & $\begin{array}{l}\text { Vuelta a un estado de fuerte deterioro } \\
\text { de las estructuras. }\end{array}$ \\
\hline
\end{tabular}

largo de su historia, sufriendo todo tipo de acciones negativas, tanto naturales como antrópicas, llegando incluso en determinados momentos al expolio, como ocurrió con la parte central, el emblemata, del mosaico del 
peristilo en su ala norte, del que sólo sabemos por la huella que ha dejado su extracción que debió ser circular ${ }^{17}$.

No obstante, pese a todos estos avatares y gracias también a algunas decisiones acertadas en su momento, como fue la de volver a tapar los mosaicos aparecidos en 1868, la villa consiguió llegar hasta nuestros días.

Sin embargo, los problemas que presenta en la actualidad, una vez sacadas a la superficie las estructuras, suponen un serio peligro para su supervivencia en un futuro a corto plazo.

Hipótesis de trabajo para el futuro. Una propuesta para la musealización y puesta en valor del yacimiento

Tras comprobar el preocupante estado de conservación del yacimiento romano-visigodo, es urgente desarrollar una línea de actuación que contemple la consolidación, acondicionamiento, puesta en valor, musealización y excavación arqueológica de la villa de Santa Lucía, en ese orden de preferencia, que nos gustaría que se plasmara en un proyecto tangible que se pueda llevar a cabo para salvar el conjunto de su probable desaparición si sigue en estas condiciones.

El primer paso a dar sería el estudio de los materiales excavados hace treinta años, así como la redacción de la memoria de excavación de las campañas de 1968-1972. Consideramos que ésta es la base fundamental para los siguientes trabajos.

Los materiales cerámicos, fragmentos de estuco, algunos huesos y metales pertenecientes a la villa, se depositaron en un viejo almacén del ayuntamiento del pueblo, en cajas apiladas. Y así están todavía, tal y como se dejaron hace treinta años, con las cajas inferiores aplastadas por el peso sostenido durante todo este tiempo, algunas de ellas ni siquiera conservan ya las etiquetas, siendo imposible su contextualización y con los materiales mezclados (pensamos que debido a manipulaciones sucedidas durante estas tres décadas) ${ }^{18}$. Además, urge su limpieza, catalogación y

17 Incluso se sabe que en el siglo xvIll, en época de Juan de Villanueva, se arrancaron mosaicos de diferentes villas romanas para decorar el palacio de Aranjuez, y que actualmente se encuentran en paradero desconocido. Pero sí queda noticia de que algunos de esos mosaicos provenían de la zona de Segovia.

i8 En cambio, los materiales procedentes de las tumbas visigodas y sus ajuares se trasladaron al Museo Provincial de Segovia. Existe un «Inventario de los objetos procedentes de Aguilafuente" de 1968, y creemos que se conservan todos en el actual museo, cerrado estos úl- 
estudio en los próximos meses ya que el Ayuntamiento ha decidido reformar este espacio para habilitarlo como sala de exposición de la obra escultórica del artista Florentino Trapero.

Tras esta primera actuación de recuperación de la información de la excavación de los setenta, se debería presentar un proyecto de intervención en el yacimiento.

Dicho proyecto podría comprender, a modo de sugerencia, distintas fases de actuación en función de las necesidades del conjunto:

1. ${ }^{\circ}$ FASE: Consolidación de estructuras emergentes. Esta fase es fundamentalmente de tipo preventivo, comenzando por el cercado del yacimiento y la creación de un sistema de drenaje. Además, se propondría la señalización del yacimiento, así como la instalación de un par de paneles (uno sobre la villa y otro sobre la necrópolis de época visigoda) explicativos que completen sobre el campo lo expuesto en el aula arqueológica del pueblo. Por supuesto, no faltaría en este proyecto la consolidación de los muros. También sería parte básica la eliminación del biodeterioro.

2. ${ }^{a}$ FASE: Tendría lugar después de que se cumplieran todas las condiciones del primer proyecto. En esta fase se propone la excavación de la otra parte que falta por documentar, así como la zona oeste al exterior de la villa, por donde se sabe que continuaban los enterramientos.

Lo primero que se propondría sería la prospección intensa de la zona en función de determinados topónimos que nos pueden estar hablando de yacimientos romanos que podrían estar en relación, a buen seguro, con la propia villa de Santa Lucía. Destacan dos topónimos: en las proximidades del yacimiento (a $300 \mathrm{~m}$ ) se encuentra un paraje denominado "Cerco de Roma", lo que nos sugiere, por su toponimia y la abundancia de materiales de construcción (tejas) conservados allí, la existencia de otra estructura dependiente de la villa. El otro topónimo está un poco más alejado (en el término de Sauquillo) pero es igual de interesante, pues se llama "Sexmo romano».

A continuación, se desarrollaría la excavación arqueológica en la villa.

3. ${ }^{a}$ FASE: Esta fase es sin duda la más importante y la que culmina las dos anteriores. Consistiría en la musealización del yacimiento y su aprovechamiento turístico y cultural. Es la parte más ambiciosa.

timos años. De todas formas, tampoco se ha hecho un estudio y publicación de dichos materiales, a excepción de las fíbulas de tecnología trilaminar, publicadas por R. Lucas en el noticiario arqueológico de los Trabajos de Prehistoria (1977). 
Se partiría con una posición ventajosa, pues la villa ya cuenta con un aula arqueológica situada en el pueblo, a $2 \mathrm{Km}$ del yacimiento, totalmente equipada de cara a una función principalmente didáctica enfocada a alumnos de Educación Secundaria y Primaria, por lo que se puede contar con un público muy amplio. El aula arqueológica se puso en funcionamiento en octubre de 2001 y de momento está teniendo relativo éxito (tendría más con una mayor publicidad de la misma y con la posibilidad de ofrecer la visita al yacimiento in situ).

Por otro lado, se buscaría, o intentaría por lo menos, la recuperación del entorno natural original o el más antiguo posible. Aquí tiene especial importancia la variada masa forestal de la que hablábamos al principio. Así, podrían convivir especies como encinas, robles jóvenes, saúcos y, por supuesto, pinos, en determinadas zonas del yacimiento, como podría ser el camino de acceso o en las delimitaciones del conjunto arqueológico.

Una vez llegados a la villa, ésta se visitaría por un camino trazado a modo de pasarela, sin pisar ninguna zona del yacimiento. Como ya se ha hecho en otras villas, uno de los puntos más importantes de este proyecto sería la reintegración de los mosaicos y las pinturas murales en sus sitios originales, lo que haría mucho más atractiva la visita. Los materiales estudiados pasarían al aula arqueológica, mientras que en una zona determinada de la villa, se podría hacer una reconstrucción de cómo eran los enterramientos, así como de su ajuar.

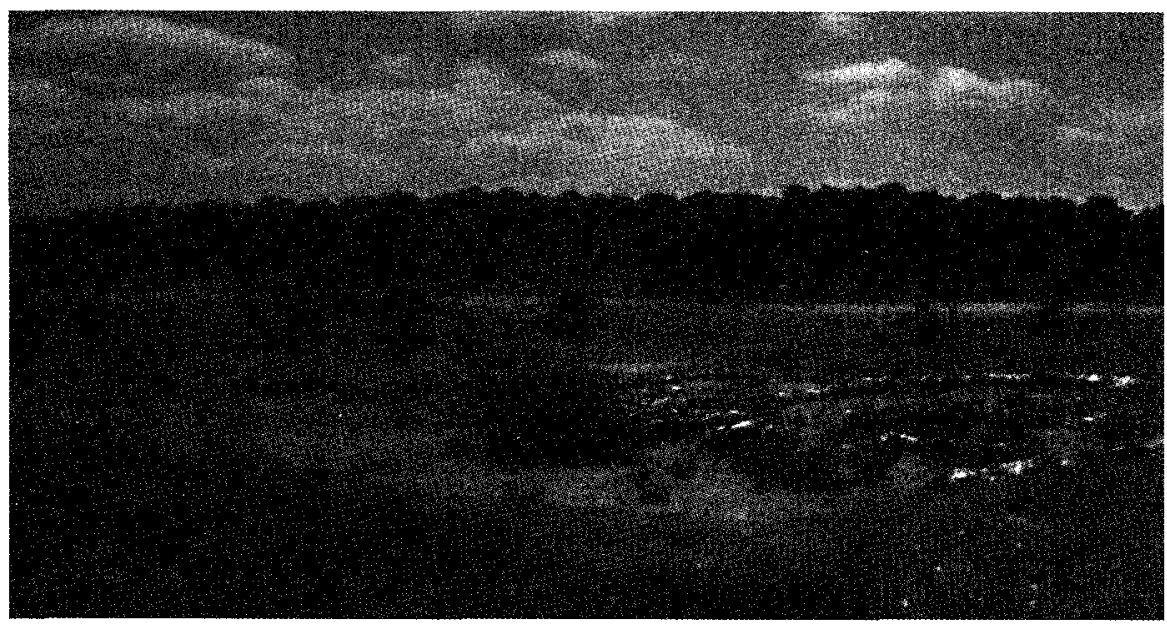

Figura 6. 
Estas son algunas ideas que nos gustaría que se pudieran convertir en realidad en el futuro. Somos conscientes de las dificultades que plantean este tipo de proyectos, pero esperamos que, por lo menos, se pueda frenar el proceso de degradación que sufre la villa de Santa Lucía, y que se pueda realizar su acondicionamiento y puesta en valor para que no quede olvidada entre las tierras de labor de un pueblo de la provincia de Segovia (fig. 6).

\section{BIBLIOGRAFIA}

ADP DE AGRICULtura: «Hojas de Cultivo», término de Aguilafuente, año 1980.

Archivo Parroquial de Agullafuente: Libro de Tazmías, (1788-1838), Iglesia Parroquia de Santa María.

Barrios García, Á.: «Repoblación de la zona meridional del Duero. Fases de ocupación, procedencias y distribución espacial de los repobladores». Studia Historica, 1985, III (2), págs. 33-82.

CSIC, Enciclopedia Lingüística Hispánica. Madrid, 1960.

CABrera GarRido, J. M. a: Alteración y conservación de materiales pétreos en los Monumentos, Tesis Doctoral, Universidad Autónoma de Madrid, 1973.

Cabrera Garrido, J. M.a: "Causas de alteración y métodos de conservación aplicables a los monumentos hechos con piedra", Revista Materiales de Construcción, n. ${ }^{\circ} 174$, abril-mayojunio 1979. Consejo Superior de Investigaciones Científicas, Instituto Eduardo Torroja.

CORTÁZAR, D. DE: Descripción física y geológica de la provincia de Segovia, Madrid, 1891.

DíEz SANZ, J.J.: «El Hospital de los pobres La Cruz y la tradición sanitaria de Aguilafuente». Suplemento de El Adelantado de Segovia, 24 y 31 de enero de 1984.

DíEZ SANZ, J.J.: «El yacimiento arqueológico de Sta. Lucía de Aguilafuente: un olvido de la administración." Suplemento de El Adelantado de Segovia, 4 y 11 de diciembre de 1986.

DíEz SANZ, J.J.: «San Juan Bautista de Aguilafuente. Lazo de unión del románico segoviano.» Suplemento de El Adelantado de Segovia, 14 de junio de 1984.

DIEZ SANZ, J.J.: Historia de Aguilafuente (Segovia). Causa de la imprenta española. Gráficas Ballesteros. Alcalá de Henares (Madrid), 1992, reeditado en 2001.

Fernández CASTRO, M. ${ }^{2}$. C.: Villas romanas en España. Ministerio de Cultura, Dirección General de Bellas Artes, Madrid, 1982.

FERNÁNDEZ IBÁNEEZ, C.: «Arqueología y conservación. Una visión general». Espacio, Tiempo y Forma. Serie III, Tomo I. Homenaje al profesor Eduardo Ripoll Perelló. UNED. Madrid, 1988 págs.427-442.

LECEA Y GARCÍA, C.: "Los mosaicos de Aguilafuente», Miscelánea Bibliográfico-literaria y Variedades Segovianas, Segovia, 1915, 23-26.

LUCAS, M.a R., "La influencia africana en la iconografía equina de la villa de Aguilafuente», CUPAUAM 13-14, Madrid, 1986-1987, 219-235.

LUCAS, M. ${ }^{\text {a }}$ R. y VINAS, V.: «Nuevos mosaicos romanos y otros hallazgos arqueológicos en la provincia de Segovia", Estudios Segovianos, Tomo XIII, 1971.

LUCAS M. ${ }^{a}$. R. y VINAS, V.: "La villa romana de Aguilafuente (Segovia)», en Segovia. Symposium de Arqueología Romana. Bimilenario de Segovia. Universidad de Barcelona y Caja de Ahorros de Segovia, Publicaciones Eventuales n. ${ }^{\circ}$ 27, Barcelona, 1977. págs. 239-255.

LUCAS, M. ${ }^{a}$ R. y VIÑAS, V.: "Tecnología de la fíbula trilaminar de la necrópolis visigoda de Aguilafuente (Segovia)», Trabajos de Prehistoria, XXXIV, 1977, 389-404.

MaPa Geotécnico General, del Ministerio de Industria, Dirección General de Minas. Instituo Geológico y Minero de España. Hoja 5-5/38, correspondiente a la provincia de Segovia, Madrid, 1974.

MARTín EXPósITo, A., Demografía y modo de producción feudal: población y poblamiento de la diócesis de Segovia a mediados del siglo XIII. Salamanca, 1981. Memoria de Licenciatura inédita. 
Martín Rodríguez, J. M., “Aproximación a la toponimia segoviana». Estudios Segovianos. Tomo XXXV, n. ${ }^{\circ}$ 91. (Homenaje al Marqués de Lozoya), 1994.

MEnÉndez PIDAL, R., Toponimia prerrománica hispana. Ed. Gredos, Madrid, 1968.

Molinero Pérez, A., "Aportaciones de las excavaciones y hallazgos casuales (1941-1959) al Museo Arqueológico de Segovia». Excavaciones Arqueológicas en España, n. ${ }^{\circ} 72$. Lámina CLXVI, 2. Madrid, 1971, 70 .

Molinero PÉrez, A., "Diez años de arqueología segoviana». Estudios Segovianos. Tomo II, 1950.

Represa Rodríguez, A., "La antigua provincia de Segovia». Estudios Segovianos, Tomo XXI, 1969.

SÁez, E. (ed.), Colección diplomática de Cuéllar. Dip. Prov. de Segovia, Segovia, 1961.

SANZ NÁJERA, M. S., «Técnica de consolidación y extracción de estructuras completas en yacimientos arqueológicos". Actas de las Primeras Jornadas de Metodología de Investigación Prehistórica. Madrid, 1984, págs.453-457.

Siguero LloRENTE, Pedro Luis, Significado de los nombres de los pueblos y despoblados de Segovia. 1997.

SyMPosium De ARQUeOlogía RomAnA, Segovia y la arqueología romana. Instituto de Arqueología y Prehistoria. Edit. Universidad de Barcelona, 1971.

VILLAR García, L.M., Documentación medieval de la catedral de Segovia. 1115-1300. Colección Textos Medievales, 15. Universidad de Salamanca y Univ. de Deusto, 1990.

VV. AA., Segovia Romana, Caja Segovia, Segovia, 2000.

Página Web: MOLINA, J. J., aula_arqueológica, 2002. 